\title{
Sobre la circulación de las primeras ediciones impresas del Digesto en el contexto histórico- jurídico de las Reales Audiencias de Santa Fe de Bogotá y de San Francisco de Quito (siglos XVI-XVIII)
}

\section{On the Circulation of the First Printed Editions of the Digest in the Changing Context of the Santa Fe de Bogota and San Francisco de Quito Royal Audiences $\left(16^{\text {th }}-18^{\text {th }}\right.$ centuries $)$}

Juan Carlos PRADO RODRÍGUEZ

Profesor de Derecho Romano

Departamento de Derecho Privado. Facultad de Ciencias Sociales y Jurídicas

Universidad Carlos III de Madrid

jprado@der-pr.uc3m.es

Recibido: 9 de diciembre de 2010

Aceptado: 24 de febrero de 2011

\section{RESUMEN}

Se estudian en el presente trabajo las relaciones de la ciencia jurídica romanista, a través de su magna obra, el Digesto de Justiniano, con el Derecho Indiano, más concretamente, las ediciones que llegaron a las Reales Audiencias de Santa Fe de Bogotá y de San Francisco de Quito. Estas ediciones del Digesto, que estaban en los antiguos archivos y bibliotecas de dichas ciudades andinas, demuestran que el derecho romano estaba presente el derecho indiano y dicha aplicación no fue simplemente desde un aspecto formal sino material, como lo demuestra la gran cantidad de ediciones existentes en estos territorios apenas descubiertos.

PALABRAS CLAVE: Digesto, Audiencia de Santa Fe de Bogotá, Audiencia de San Francisco de Quito, Derecho Romano, Derecho Indiano.

\begin{abstract}
The present work reviews the relations of Indianous Law with Romanist legal science, through its main work, Justinian's Digest. More specifically, it deals with the issues that came to the Royal Audiences of Santa Fe de Bogota and San Francisco de Quito. The editions of the Digest found in these Andean cities' old archives and libraries prove that Roman law was present in Indianous law and that such application was not simply formal but also material, as evidenced by the large number of editions existing in those hardly discovered territories.
\end{abstract}

KEYWORDS: Digest, Audience of Santa Fe de Bogota, Audience of San Francisco de Quito, Roman law, Indianous Law. 


\section{RÉSUMÉ}

On va étudier dans ce travail les relations de la science juridique romaniste, d'après sa magne oeuvre, le Digeste de Justinien, avec le droit indien. Plus précisément, les questions qui sont venus aux Audiences royales de Santa Fe de Bogota et de San Francisco de Quito. L'éxistence d'éditions du Digeste, conservées dans les anciens archives et bibliothèques de ces villes andines, démontrent que le droit romain a été présente dans le droit indien et que cette demande n'était pas simplement formelle mais matérielle, comme en témoigne le grand nombre existant de ces éditions dans des territoires à peine découverts.

MOTS CLÉ : Digeste, Audience royale de Santa Fe de Bogota, Audience royale de San Francisco de Quito, droit romain, droit indien.

\section{ZUSAMMENFASSUNG}

In diesem Artikel werden die Beziehungen der romanistischen Rechtswissenschaft anhand ihres Hauptwerkes, den Digesten Justinians, mit dem Derecho indiano nachgezeichnet, und zwar konkret an den Ausgaben, die zu den Reales Audiencias de Santa Fe de Bogotá und San Francisco de Quito kamen. Die Digesten-Ausgaben, welche in den ehemaligen Archiven und Bibliotheken dieser Andenstädte lagen, zeigen auf, dass das Römische Recht im derecho indiano gegenwärtig war und dass seine Anwendung nicht bloß aus einem formalen Gesichtspunkt, sondern aus materieller Sicht kam, was die große Anzahl an dort vorhandenen, kaum entdeckten Ausgaben belegt.

SCHLÜSSELWÖRTER: Digesten, Audiencia de Santa Fe de Bogotá, Audiencia de San Francisco de Quito, Römisches Recht, Derecho indiano.

SUMARIO: 1 . Introducción. 2. El contexto histórico-jurídico en Castilla y en las Indias Occidentales en el siglo XVI. 3. Aspectos concernientes al transporte y la censura de libros hacia las Indias. 4. Algunas ediciones impresas del Digesto en los fondos antiguos de Santa Fe de Bogotá y de San Francisco de Quito. 5. Observaciones conclusivas.

\section{Introducción}

Resulta de gran interés para la ciencia jurídica romanística lograr conocer el iter a través del cual el Digesto de Justiniano llegó desde Europa a los territorios de las Indias occidentales a partir del siglo XVI. En este sentido, y de forma particular, el presente estudio tiene la finalidad de mostrar, aunque a grandes rasgos, algunos de los aspectos históricos y materiales concernientes a la circulación de las primeras ediciones impresas del Digesto que llegaron a las ciudades sedes de lo que fueron las Reales Audiencias de Santa Fe de Bogotá ${ }^{1}$ y de San Francisco de Quito ${ }^{2}$ en el Nuevo

\footnotetext{
${ }^{1}$ Creada por Carlos V con Real Cédula del 17 de Junio de 1549 dada en Valladolid, vd. Recopilación de leyes de los Reinos de las Indias mandadas a imprimir y publicar por la Majestad Católica del Rey. Don Carlos II, Madrid, 1681, libro II, título XV (De las Audiencias y Cancillerias Reales de las Indias), ley VIII (Audiencia y Cancilleria Real de Santa Fe en el Nuevo Reyno de Granada); A. García-Gallo, Los orígenes españoles de las instituciones americanas. Estudios de Derecho Indiano, Madrid, 1987, pp. 933, nt. 226.

${ }^{2}$ Creada por Felipe II con Real Cédula del 29 de noviembre de 1563 dada en Guadalajara, vd. Recopilación de leyes de los Reinos de las Indias cit., ley X (Audiencia y Cancilleria Real de San Francisco
} 
Mundo ${ }^{3}$; organismos estos que estuvieron al servicio de la Corona española hasta el año 1717, cuando el monarca Felipe V instauró el Virreinato de Nueva Granada, englobando así a las mencionadas Audiencias en un único marco territorial y jurisdiccional conjuntamente a otros territorios ${ }^{4}$.

La elección del ámbito territorial y cronológico tomado en consideración corresponde al hecho de que era en las Audiencias en donde se administraba la justicia para los territorios en los que éstas tenían competencia judicial ${ }^{5}$, y porque el lapso de tiempo que va desde la instauración de la Real Audiencia de Santa Fe de Bogotá (1549) coincide con el período de la historia colonial en el que se intensificó el transporte de libros hacia las Indias occidentales ${ }^{6}$, y por ende, con la circulación de ediciones del Digesto procedentes de Europa ${ }^{7}$, donde tuvo un rol crucial para tal respecto el orden religioso de los Jesuitas, representado por la Compañía de Jesús, en función hasta el año 1767 , cuando serían expulsados de los territorios y dominios españoles por voluntad de Carlos III.

En este sentido se documentarán algunas de las ediciones impresas y bibliografías que del Digesto circularon entre los siglos XVI y XVIII ${ }^{8}$, y que se encuentran en los Fondos y bibliotecas de las ciudades de Santa Fe de Bogotá y de San Francisco de

de Quito); A. García-Gallo, Los orígenes españoles de las instituciones americanas. Estudios de Derecho Indiano cit., pp. 933, nt. 228.

${ }^{3}$ Sobre tal expresión vd. S. Schipani, "El derecho romano en el Nuevo Mundo", Sistema Jurídico Latinoamericano y Unificación del Derecho (Coord. D.F. Esborraz), México, 2006, pp. 3 ss.

${ }^{4}$ Así la Real Cédula del 27 de Mayo de 1717 dada en Segovia: «[...] he resuelto que el territorio y jurisdicción que el expresado Virey, Audiencia y tribunal de cuentas de la ciudad de Santafé han de tener, es y sea toda la provincia de Santafé, nuevo reino de Granada, las de Cartagena, Santamarta, Maracaibo, esa de Caracas, Antioquía, Guayana, Popayán y la de San Francisco de Quito [...]. Yo el Rey».

${ }^{5}$ Sobre las atribuciones de las Audiencias vd. J. Sánchez-Arcilla Bernal, Las ordenanzas de las audiencias de indias (1511-1821), Madrid, 1992; A. Dougnac Rodríguez, Manual de Historia del Derecho Indiano, México, 1994, pp. 153 ss.; J. Barrientos Grandón, El gobierno de las Indias, Madrid-Barcelona, 2004, pp. 151 ss.; E. Martiré, Las Audiencias y la Administración de la Justicia en las Indias, Madrid, 2005.

${ }^{6} \mathrm{Al}$ respecto vd. I.A. Leonard, Los bienes del Conquistador, México, 1953; H. Gutiérrez Luzardo, "Circulación del libro en el Nuevo Reino de Granada", Historia de Colombia, I, n. 2-4, Bogotá, 1955, pp. 73 ss.; C.A. González Sánchez, Los mundos del libro. Medios de difusión de la cultura occidental en las Indias de los siglos XVI y XVII, Sevilla, 1999.

${ }^{7}$ Sobre el tema, J.M. Castán Vásquez, "La difusión del derecho romano en Iberoamérica a través de libros españoles", Anuario Jurídico, XI, 1984, pp. 325 ss.; J. Barrientos Grandón, "El humanismo jurídico en las librerías del reino de Chile (s. XVII -XVIII)", Revista de Derecho de la Universidad Austral de Chile, III, n.1-2, 1992, pp. 25 ss.

${ }^{8}$ Circulación que dependerá del Codex Florentinus (siglo VI o VII), ya que a partir de él se desarrolló la littera vulgata, y desde su primera impresión en 1476 en Perugia se multiplicarían, con algunas variantes, las ediciones impresas de la misma, sobre todo en ciudades como Venecia, Lyon y París, cfr. H.E. Troje, "Sobre la crítica y algunas ediciones de textos en la jurisprudencia humanística (tr. por F.J. Andrés Santos)", Revista de Estudios Históricos Jurídicos [Sección Historia del Derecho Europeo], XXXI, 2009, pp. 260; vd. al respecto E. Spagnesi (Catalogo a cura di), Le pandette di Giustiniano. Storia e fortuna della «Littera Florentina». Mostra di codici e documenti 24 gingno-31 agosto 1983, Firenze, 1983. 
Quito, para lo cual se tomarán en consideración los aspectos más relevantes de lo que fue el comercio de libros en la 'Carrera de Indias', que a través de las naves españolas eran destinados a enriquecer no sólo las bibliotecas de las primeras Universidades donde se enseñaba la ciencia jurídica en Ultramar, sino también los organismos dependientes de la Corona española donde se administraba la justicia para tales territorios.

Cabe señalar desde ahora cómo no todas las obras impresas en Europa estaban autorizadas a entrar en los territorios que se iban conquistando, debiendo antes someterse a un rígido control por parte de las autoridades civiles y eclesiásticas de la época para así evitar que en estos lugares se propaguen obras de autores que pudieran de alguna manera alterar la ortodoxia católica, de frente a las nuevas posturas dogmáticas de la Reforma Protestante en auge en algunos países europeos en los que se imprimían obras que se intentarían luego transportar al Nuevo Mundo.

Así, pues, la presencia de ediciones impresas del Digesto que integran los ricos Fondos antiguos de archivos y bibliotecas de las dos ciudades andinas, denota ampliamente cómo el derecho romano llegó, no sólo desde un punto de vista teórico a tales territorios, sino también materialmente, lo que se refleja en la gran cantidad de ediciones y bibliografías que del Digesto se difundieron en los territorios apenas descubiertos ${ }^{10}$.

\section{El contexto histórico-jurídico en Castilla y en las Indias Occidentales en el siglo XVI}

Por lo que se refiere al derecho vigente en el Reino de Castilla en el período de la conquista de las Indias, este tuvo entre sus fuentes normativas a las Siete Partidas ${ }^{11}$, fundamentadas en el derecho romano y en las aportaciones doctrinales que realizaron los Glosadores italianos, debiéndose a la labor de los juristas castellanos formados en Bolonia la producción de dicho cuerpo legislativo, cual exigencia de traducción y de síntesis de los textos del Corpus iuris civilis en un nuevo y unitario orden, integrado además por normas de derecho canónico y fueros locales del mismo Reino ${ }^{12}$.

Cabe observar a tal respecto cómo el renacimiento del derecho romano se manifestó en Bolonia desde el siglo $\mathrm{XI}^{13}$, siendo Irnerio el precursor del estudio y del en-

\footnotetext{
${ }^{9}$ Sobre el tema vd. P.J. Rueda Ramírez, Negocio e intercambio cultural: El comercio de libros en la Carrera de Indias (Siglo XVII), Sevilla, 2005; mientras que sobre los aspectos generales de la Carrera de Indias, vd. F. de Castro y Bravo, Las naos españolas en la Carrera de Indias (Armadas y Flotas en la segunda mitad del siglo XVI), Madrid, 1927.

${ }^{10}$ Como observa F. López de Somarra, Primera de la Historia General de Indias, Madrid, 1852, pp. 156: «La mayor cosa después de la creación del mundo [...] es el descubrimiento de las Indias»; al respecto vd. también L. Zea, "El descubrimiento de América y la universalización de la historia", El descubrimiento de América y su impacto con la Historia (ed. por L. Zea), México, 1991, pp. 6 ss.

${ }^{11}$ Mandadas a redactar por el monarca Alfono X 'El Sabio' entre los años de 1256 y 1265, vd. J. Sánchez-Arcilla, Las Siete Partidas, Madrid, 2004.

${ }^{12}$ Cfr. S. Schipani, Iustiniani Augusti Digesta seu Pandectae. Testo e traduzione, I, 1-4, Milano, 2005, pp. XVIII.

${ }^{13} \mathrm{Al}$ respecto vd. H. Fitting, Die Anfänfge der Rechtsschule zu Bologna, Berlin, 1888.
} 
señamiento de esta disciplina en el naciente Studium Generale de esa ciudad ${ }^{14}$, quien procedía con el método de aclarar y explicar, al margen o entre las líneas de los textos jurídicos romanos, las disposiciones de los antiguos prudentes ${ }^{15}$.

Y sería en tal contexto que el ius commune se divulgaría en Castilla, principalmente por medio de los estudiosos castellanos (ultramontanos), que una vez terminada su formación en el Alma Mater proseguían ya como docentes hacia las Universidades ibéricas, siendo la más importante la de Salamanca $(1218)^{16}$, y desde ahí el ius commune se difundirá también en los territorios castellanos de Ultramar ${ }^{17}$.

Sin embargo, por ser la recepción del derecho romano un fenómeno común a toda Europa, no por ello no surgieron dificultades a la hora de recibirlo en tierras castellanas, en donde ya existía un ius proprium ${ }^{18}$, sobre todo a causa de la desconfianza hacia quienes provenían de fuera; en efecto, los juristas castellanos no siempre aceptaron que el Corpus iuris civilis tuviera vigencia positiva en sus propios reinos al no reconocer sus monarcas dependencia del Sacro Romano Imperio, aunque terminaron por darle una vigencia doctrinal que no implicaba ninguna sujeción a dicho Imperio ${ }^{19}$.

Así pues, la Corona castellana aplicaría en los territorios de Ultramar un derecho de gran tradición romana ${ }^{20}$, ya que a partir de la primera mitad del siglo XVI el territorio conquistado se subdividió en Audiencias, Virreinatos y Capitanerías Generales,

\footnotetext{
${ }^{14}$ Vd. E. Besta, L'opera d'Irnerio. Contributo alla storia del diritto romano, 2 vols., Torino, 1896.

${ }^{15}$ Observa S. Schipani, Iustiniani Augusti Digesta seu Pandectae cit., pp. XVI: «Essi lavoravano chiarendo i testi di Giustiniano con annotazioni nel margine (glossae) che spiegavano la parola usata, attraverso una rete crescente di richiami e confronti con gli altri usi della stessa, prevalentemente interni all'opera di Giustiniano». Sobre el método de exposición de la Glossa vd. A. Fernández de Buján, "Sistemática y ius civile en las obras de Quintus Mucius Scaevola y de Accursio", Revista Jurídica de la Universidad Autónoma de Madrid, 6, 2002, pp. 75 ss.

${ }^{16} \mathrm{Al}$ respecto vd. A.M. Rodríguez Cruz, Salamantica docet. La proyección de la Universidad de Salamanca en Hispanoamérica, Salamanca, 1977.

${ }^{17}$ Sobre el tema vd. A. García-Gallo, "La ciencia jurídica en la formación del derecho hispanoamericano en los siglos XVI y XVIII", AA.VV., La formazione storica del diritto moderno in Europa, 1, Firenze, 1977, pp. 316 ss.

${ }^{18}$ Así los varios Fueros (Liber Iudiciorum - Fuero juzgo) en vigor en Castilla, y que tenían su origen en los derechos romano-barbáricos que influenciaron la península ibérica; a tal respecto observa B. Bravo Lira, "Difusión del Código civil de Bello en los países de derecho castellano y portugués", Andrés Bello y el derecho Latinoamericano. Congreso internacional, Roma 10-12 diciembre 1981, Caracas, 1987, pp. 344: «por derecho patrio o nacional se entiende fundamentalmente la legislación real de Castilla [...] entendida en los distintos cuerpos legales, tales como las Siete Partidas». Vd. también J. Barrientos Grandón, Introducción a la historia del derecho chileno, I. Derechos propios y derecho común en Castilla, Santiago, 1994.

${ }^{19}$ Cfr. A. Guzmán Brito, La codificación civil en Ibero América. S. XIX y XX, Santiago, 2000, pp. 29; al respecto vd. también R. Riaza, "El derecho romano y el derecho nacional en Castilla durante el siglo XVIII", Revista de Ciencias Jurídicas y Sociales, 12, 1929, pp. 104 ss.

${ }^{20} \mathrm{Al}$ respecto vd. A. Díaz Bialet, "La fortuna y el valor práctico de la obra de Acursio en el Derecho común Americano", Atti del Convegno Internazionale di Studi Accursiani. Bologna, 21-26 Ottobre 1963, III, Milano, 1968, pp. 1007 ss.
} 
llegando a ocupar el derecho romano un lugar en el orden de prelación de las fuentes aplicables en tales territorios por su intrínseca relación con el derecho castellano ${ }^{21}$.

Sin embargo, por derecho Indiano se debe entender el derecho creado para regular las exigencias del propio contexto territorial de Ultramar ${ }^{22}$, y muchas de sus normas se encuentran plasmadas en la Recopilación de leyes de los Reinos de las Indias mandadas a publicar por Carlos II en 168123; mientras que para la práctica jurídica de derecho privado se aplicaba prevalentemente el derecho castellano, así cada vez que no había derecho propio sobre una determinada materia, por lo que se acudía a éste cuando había que colmar un vacío en el derecho específico de Indias ${ }^{24}$.

$\mathrm{Y}$ a tal respecto hay que resaltar cómo las naves españolas transportaron a las Indias occidentales enteras bibliotecas de derecho romano común que derivaban de la obra de Justiniano, y que paulatinamente integrarían los fondos de las bibliotecas de sus primeras Universidades ${ }^{25}$, siendo la más antigua de ellas la de Santo Domingo en la Isla Española fundada en $1538^{26}$, aunque se suelen identificar como mayores a las Universidades de San Marcos de $\operatorname{Lima}^{27}$ y a la de $\mathrm{México}^{28}$, ambas fundadas en $1551^{29}$. Mientras que en las ciudades sedes de las Reales Audiencias de Santa Fe de Bogotá y de San Francisco de Quito se fundaron, respectivamente, las Universidades de Santo Tomás en 1580 y la de San Fulgencio en $1586^{30}$.

${ }^{21}$ Siendo fuentes supletorias de este derecho Indiano, las leyes de Toro, el Ordenamiento de Alcalá, los Fueros municipales, el Fuero Real y las Siete Partidas, cfr. R. Rodríguez López, "El derecho romano en las codificaciones iberoamericanas", Contemporaneidad de los clásicos en el umbral del tercer milenio. Actas del congreso internacional de los clásicos. La tradición grecolatina ante el siglo XXI, del 1 al 5 de diciembre de 1998 (ed. por M. Pérez Morán), La Habana, 1999, pp. 380. Sobre la aplicación del derecho común en América castellana vid. A. García-Gallo, "El derecho común ante el nuevo mundo", Revista de Estudios Políticos, 80, 1955, pp. 133 ss.; Id., "La penetración de los derechos europeos y el pluralismo jurídico en la América española 1492-1824”, Index, 6, 1976, pp. 3 ss.; Id., Estudios de historia del derecho Indiano, Madrid, 1972; C. Petit, "El caso del derecho Indiano", Quaderni Fiorentini, 22, 1993, pp. 665 ss.; F. Camacho Evangelista, "Granada y el Derecho en América”, Revista de la Facultad de Derecho de la Universidad de Granada, 1998, pp. 399 ss.

${ }^{22}$ Observa B. Bravo Lira, Derecho común y derecho propio en el nuevo mundo, Santiago, 1989, pp. 5: «Se llama derecho Indiano el que rigió en América española desde la época de los descubrimientos hasta la codificación [...] desde finales del siglo XV hasta la segunda mitad del XIX».

${ }^{23} \mathrm{Al}$ respecto vd. J. Manzano, Historia de las Recopilaciones de Indias, 2 vols., Madrid, 1950-1956.

${ }^{24}$ Cfr. B. Bravo Lira, Derecho común y derecho propio en el nuevo mundo cit., pp. 8.

${ }^{25}$ Cfr. S. Schipani, Iustiniani augusti Digesta seu Pandectae cit., pp. XX.

${ }^{26}$ Bula In apostolatus culmine de Papa Paulo III dada en Roma el 28-X-1538.

${ }^{27}$ Real provisión de Carlos V dada en Valladolid del 12-V-1551/Breve Exponi nobis nuper de San Pío $\mathrm{V}$ dada en Roma el 25-VII-1571.

${ }^{28}$ Real Cédula del príncipe don Felipe II dada en Toro el 21-IX-1551/Bula Ex supernae dispositionis arbitrio del 7-X-1595.

${ }^{29}$ Cfr. F. Betancourt, "Sobre la recepción del derecho romano en Colombia (Saec. XVII-XVIII)", Estudios Calonge, I, Salamanca, 2002, pp. 83 ss.; Id., La recepción del derecho romano en Colombia (Saec. XVIII). Fuentes codicológicas jurídicas I: Ms. n. 274 BNC, Sevilla, 2007, pp. 203 ss.; sobre el tema vd. A.M. Rodríguez Cruz, Historia de las Universidades Hispanoamericanas. Período Hispánico I, Bogotá, 1973. ${ }^{30}$ Vd. F. Betancourt, "Sobre la recepción del derecho romano en Colombia” cit., pp. 83 ss. 
En este sentido los catálogos y ficheros de estas antiguas instituciones académicas conservan las referencias acerca de cuáles fueron las obras jurídicas de mayor difusión en tal contexto universitario ${ }^{31}$, sin olvidar las bibliotecas privadas que posteriormente serían donadas a las mismas Universidades, y en las que con seguridad existieron ediciones del Corpus iuris civilis ${ }^{32}$. Sin embargo, antes de que sean las Universidades a colmarse de la abundante literatura jurídica llegada desde Europa, fueron los conventos de las distintas órdenes religiosas, como los Franciscanos, Dominicos, Agustinos y Jesuitas, los que guardaban, y lo hacen aún, los preciosos volúmenes de derecho romano y canónico (utrumque ius) provenientes de Europa ${ }^{33}$.

De tal manera la ciencia jurídica romana llegaría, a través de la praxis doctrinal iniciada en Bolonia, hasta Castilla ${ }^{34}$, y por consecuencia también a sus dominios en Ultramar $^{35}$, resultando interesante a tal respecto observar las principales fases que marcaron las pautas de lo que fue la circulación de las primeras ediciones impresas del Digesto hacia los territorios castellanos en los que desempeñaron su función las Reales Audiencias de Santa Fe de Bogotá y San Francisco de Quito.

\section{Aspectos concernientes al transporte y la censura de libros hacia las Indias}

Desde que se inventó la imprenta hacia mediados del siglo XV, la producción editorial en Europa tuvo un gran desarrollo, lo que determinó también la impresión de ediciones y comentarios del Digesto de Justiniano, por lo que el siglo XVI se caracterizará por la circulación de este tipo de obras provenientes de autores del humanismo jurídico, en auge en Europa en aquél entonces ${ }^{36}$.

\footnotetext{
${ }^{31}$ A tal respecto se puede observar como la Universidad de San Marcos de Lima tuvo un papel fundamental para la formación de los juristas en América y la prueba de ello es la presencia de un rico Fondo antiguo con obras de derecho romano común imprimidas en Alemania, España e Italia, vd. al respecto G. Dolezalek, "Libros jurídicos anteriores a 1800 en la Biblioteca de la Universidad Nacional Mayor de San Marcos de Lima. Bases para la formación jurídica de los abogados latinoamericanos del siglo XIX", Studi Sassaresi (Diritto romano, codificazioni e sistema giuridico latinoamericano), 5, Milano, 1981, pp. 491 ss.

${ }^{32}$ Vd. J.M. Castán Vásquez, "La difusión del derecho romano en Iberoamérica a través de libros españoles" cit., pp. 330.

${ }^{33}$ Cfr. J.M. Castán Vásquez, "La difusión del derecho romano en Iberoamérica a través de libros españoles" cit., pp. 328.

${ }^{34}$ Según el iter tradicional del Sistema jurídico romanístico, vd. S. Schipani, La codificazione del diritto romano comune. Studi su origine ed attualità del sistema romano, 2, Torino, 1999, pp. 49.

${ }^{35}$ Así el ius commune sería introducido en las Universidades Hispanoamericanas desde sus comienzos por letrados peninsulares formados en las universidades de la Metrópoli, y luego por las generaciones universitarias nacidas en las Indias, cfr. F. Betancourt, La recepción del derecho romano en Colombia (Saec. XVIII) cit., pp. 544.

${ }^{36} \mathrm{Al}$ respecto vd. P. Koschaker, Europa und das römische Recht, München, 1947, 105 ss.; D. Maffei, Gli inizi dell'umanesimo giuridico, Milano, 1956; H.E. Troje, Humanistische Jurisprudenz, Golbach, 1993; Id., "Ubi in libro Florentino duae lectiones inveniuntur...". Zur Geschichte der Digesteneditionem (16.-19. Jh.)", Tijdschrift voor Rechtsgeschiedenis/Revue d'historie du Droit/ The legal History Review,
} 
Así pues, plasmada en forma de libros, la doctrina jurídica romanística se trasladaba a bordo de las naves españolas hacia las Indias occidentales ${ }^{37}$, siendo por lo tanto fuente de primer orden para conocer cuáles fueron las obras jurídicas que desde el siglo XVI llegaron por esa vía a tales territorios, los registros que se conservan acerca de las cargas que transportaban las mencionadas naves, y que se encuentran en el Archivo de Indias de Sevilla, ya que cuando entre las mercancías de las naves habían libros, éstos se anotaban en el registro de bordo con la indicación expresa de las obras y el número de ejemplares de cada título de las mismas ${ }^{38}$.

Esta masiva producción editorial que se produjo en el siglo XVI determinó el traslado de obras jurídicas hacia América con la finalidad de enriquecer las bibliotecas que estaban floreciendo en los primeros centros universitarios donde se enseñaba la ciencia jurídica. Y efectivamente, entre las listas de libros transportados a las Indias se encuentran numerosas obras de derecho castellano, como las Siete Partidas glosadas por Don Gregorio López, pero también obras de derecho romano, ya que las Universidades, y las mismas Audiencias donde se administraba la justicia en tales territorios, sintieron enseguida la necesidad de crear sus propias bibliotecas para la formación y para la consulta de quienes fuesen interesados ${ }^{39}$.

A consecuencia de ello comenzaron a difundirse algunos mecanismos de control para evitar la llegada a las Indias de libros prohibidos, por lo que a mediados del siglo XVI los libros pasaban de inscribirse de forma genérica en los registros de los embarques que los habrían transportado, a describirse de forma detallada, expresando los títulos contenidos en ellos ${ }^{40}$.

Esta vigilancia se llevaba a cabo en el momento de embarcar las obras en la aduana del puerto de Sevilla ${ }^{41}$, a la cual se unía su revisión en los puertos de destino en Indias al momento del desembarque ${ }^{42}$.

72, 2004, pp. 61 ss.; Id., Sobre la crítica y algunas ediciones de textos en la jurisprudencia humanistica cit., pp. 259 ss.

${ }^{37}$ Observa J.M. Castán Vásquez, "La difusión del derecho romano en Iberoamérica a través de libros españoles" cit., pp. 331: «Constituyendo el derecho romano, en buena parte, la base del derecho español, y habiendo sido los textos de Gayo y Justiniano objeto de estudio o de consulta constante para los juristas españoles [...] es natural que a partir del descubrimiento y de la Conquista los españoles llevasen a América ejemplares de las ediciones de los textos romanos impresos en España. No faltan pruebas de ello. Así, en el registro de libros que Luis Padilla, vecino de Sevilla, enviaba en la nao "Trinidad" que va a la provincia de Nueva España, en el año de 1600, figuraban las Ynstituciones juris cibilis con glosas». ${ }^{38}$ Cfr. J.M. Castán Vásquez, "La difusión del derecho romano en Iberoamérica a través de libros españoles" cit., pp. 326.

${ }^{39}$ Cfr. J.M. Castán Vásquez, "La difusión del derecho romano en Iberoamérica a través de libros españoles" cit., pp. 327.

${ }^{40}$ En efecto, observa P.J. Rueda Ramírez, Negocio e intercambio cultural: El comercio de libros en la Carrera de Indias (Siglo XVII) cit., pp. 66: «la Corona ordena a la Casa de Contratación de Indias en Sevilla que [...] cuando hubieren de llevar a las Indias algunos libros de los permitidos, los hagan registrar específicamente cada uno, declarando la materia de qué trata, y no se registren por mayor».

${ }^{41}$ Observa F. Betancourt, La recepción del derecho romano en Colombia (Saec. XVIII) cit., pp. 538: «En el siglo XVI el río Guadalquivir, con sus fondeaderos y el puerto de Sevilla, se erigió en la columna 
Sin embargo, de este mero control aduanero se pasó muy pronto a una vigilancia inquisitorial ${ }^{43}$; en efecto, las señales de alarma ante la penetración de libros prohibidos llevaron a la Corona española a tomar medidas para sancionar a quienes los introducían, por lo que hacia el año 1579 el Consejo de Castilla, conjuntamente con el de Indias, establecieron la preeminencia del Santo Oficio para el control del comercio de libros, el cual se llevaba a cabo, según refiere Betancourt ${ }^{44}$, de la siguiente forma: una vez llegados a puerto los barcos extranjeros y los de Castilla que comerciaban con el exterior, un Comisario, un Notario y un familiar con dos justicias subían al navío (al cual no podía entrar ni salir nadie más) para tomar profesión de Fe del maestre y proceder a revisar las mercaderías y los camarotes de la tripulación, mientras que la descarga de tales mercancías era vigilada por el mismo Comisario, y una vez en tierra se volvía a comprobaba su contenido.

De tal manera, en la aduana de Sevilla quedaban almacenados los libros que se habían transportado hasta que el pase de un Calificador quedaba reflejado en la lista de los títulos de las obras revisadas, y luego las cajas eran selladas con el sello del Santo Oficio ${ }^{45}$.

Por lo que concierne al embarque de libros hacia las Indias, este seguía también un iter bien determinado: en primer lugar los cajones de libros se transportaban a la aduana de Sevilla para pagar los derechos y registrarlos en el navío donde se cargarían, y donde se quedarían hasta que el cargador presentara una memoria de los títulos conjuntamente al pase de un Calificador del Santo Oficio ${ }^{46}$.

Obtenido el pase de embarque se debían sellar los cajones de libros con el sello de cera del Santo Oficio, y una vez entregado en la aduana el documento con el pase del mencionado Calificador se iniciaban los trámites que permitirían la salida de los almacenes hacia dicho embarque ${ }^{47}$.

vertebral de la ciudad y en el cordón umbilical con el resto del mundo que la nutría. En Sevilla la zona portuaria estaba entre la Torre del Oro y la Puerta de Triana, Arenal [...] los almacenes de la Aduana de Sevilla estaban sitos en las Reales Atarazanas [...] originalmente destinadas a la fabricación, reparación y carenado de navíos».

${ }^{42}$ Sobre los aspectos generales relacionados con la carga y descarga de los navíos en las Indias vd. Recopilación de leyes de los Reinos de las Indias cit., libro IX, título XXXIV (De la carga y descarga de los Navios).

${ }^{43}$ Observa P.J. Rueda Ramírez, Negocio e intercambio cultural: El comercio de libros en la Carrera de Indias (Siglo XVII) cit., pp. 66, nt.12: «los oficiales reales examinaban los que llegaban por mar, y entregaban a los arzobispos los prohibidos y sospechosos para que los sometiesen al mismo proceso de censura que en España [...] para impedir la entrada de libros que "no sean católicos y examinados"».

${ }^{44}$ F. Betancourt, La recepción del derecho romano en Colombia (Saec. XVIII) cit., pp. 536 ss.

${ }^{45}$ Cfr. F. Betancourt, La recepción del derecho romano en Colombia (Saec. XVIII) cit., pp. 538.

${ }^{46}$ Observa F. Betancourt, La recepción del derecho romano en Colombia (Saec. XVIII) cit., pp. 539: «Los calificadores emplean como fórmula de estilo las escuetas palabras de que los libros "no son prohibidos" o que "son de los permitidos". Los inquisidores dan por buena la firma de cualquiera de los calificadores para obtener el pase para el embarque de los libros con destino a los puertos de Indias».

${ }^{47}$ Vd. F. Betancourt, La recepción del derecho romano en Colombia (Saec. XVIII) cit., pp. 539. 
Llegada la mercancía al puerto de destino en Indias el trámite volvía a activarse para su desembarque mediante la verificación de lo que allí registrado coincidía con los cajones desembarcados, y que estos estaban intactos y completos de los sellos del Santo Oficio, sin que falte ninguno ni se encuentren los cajones abiertos. Además, el maestre debía mostrar una copia del registro a los oficiales reales, la cual facilitará también la entrega de las mercancías a los destinatarios, es decir, serviría para que aquél a cuyo nombre estaban registradas las mercancías pudiese recogerlas ${ }^{48}$.

Este era en síntesis el iter por el cual se desarrollaba el control para embarcar y desembarcar los libros que se transportaban hacia las Indias, y en el que se puede observar cómo tuvo un rol de gran relevancia la Santa Inquisición ${ }^{49}$; en efecto, ya el Concilio V de Letrán del 1515 empezó a conceder a los obispos en Europa el poder de otorgar licencias para la impresión de libros, pero estos apenas se imprimían y los controles al inicio de esta censura fueron ligeros. Sin embargo, la llegada de la Reforma Protestante supuso un cambio radical al generar la producción de una amplia literatura polémica, a la que se intentó poner fin mediante guías de libros prohibidos en forma de Índices ${ }^{50} \mathrm{y}$ distribuidos por los tribunales ${ }^{51}$, siendo comprensible que se prestara gran atención a las publicaciones al ser estas un poderoso instrumento de difusión de ideas. De tal forma los libros eran examinados por el Santo Oficio con extremado celo, y para ello desde 1559 la Inquisición publicó varios catálogos y expurgatorios de libros prohibidos ${ }^{52}$, como el de 1583/4 llamado de Quiroga por el nombre del Inquisidor general ${ }^{53}$.

${ }^{48}$ Cfr. P.J. Rueda Ramírez, Negocio e intercambio cultural: El comercio de libros en la Carrera de Indias (Siglo XVII) cit., pp. $71 \mathrm{s.}$

${ }^{49}$ En efecto, por petición de los Reyes Católicos, el Papa Sixto IV expidió la Bula Exigit sincerae devotionis affectus del 1-XI-1478, por la cual se introdujo en Castilla dicha institución para perseguir las desviaciones doctrinales de la ortodoxia católica, cfr. F. Betancourt, La recepción del derecho romano en Colombia (Saec. XVIII) cit., pp. 518.

${ }^{50}$ Siendo el primer Índice publicado por la Universidad de París en 1542, mientras que el primero que se utilizó en España, publicado bajo los auspicios del Inquisidor general Valdés en 1551, no era más que una reimpresión del Índice compilado por la Universidad de Lovaina en 1550 con un apéndice dedicado a los libros españoles, cfr. F. Betancourt, La recepción del derecho romano en Colombia, cit., pp. 518.

${ }^{51}$ Por lo que existen al menos cinco Índices publicados entre 1551 y 1552 por los tribunales de Toledo, Valladolid, Valencia, Granada y Sevilla, cfr. F. Betancourt, La recepción del derecho romano en Colombia (Saec. XVIII) cit., pp. 518.

${ }^{52}$ Observa F. Betancourt, La recepción del derecho romano en Colombia (Saec. XVIII) cit., pp. 522: «este catálogo introdujo un expurgatorio que se publicó como texto independiente en 1584: esta innovación trató de rescatar a algunos autores y obras censuradas. El expurgatorio indica los pasajes que debían ser borrados de los textos -de ahí la expresión jurídica de autores damnati, luego de lo cual podían ser devueltos a sus dueños y circular. Al proceder de esta manera, la Inquisición española respondió de un lado a los reclamos de los intelectuales, profesores universitarios, etc., que manifestaban la necesidad de leer tales obras, y de otro a las demandas de los impresores y bibliotecas que exigían compensaciones financieras por el perjuicio derivado de la confiscación de las obras prohibidas».

${ }^{53}$ Sobre las reglas del catálogo vd. F. Betancourt, La recepción del derecho romano en Colombia (Saec. XVIII) cit., pp. 520 ss. 
En el siglo XVII se publicaron una serie de Índices, como en 1612, el cual fue promulgado por el Inquisidor general Sandoval y Rojas, y se caracterizaba por apartarse de la práctica anterior, ya que en vez de publicarse en dos volúmenes separados para libros prohibidos y expurgados, como se hizo en el del 1583/4, el tribunal publicó ambos juntos en un Index prohibitorum et expurgatorum ${ }^{54}$.

Durante la primera mitad del siglo XVIII aparecieron algunos catálogos, donde hay que resaltar el Novissimus librorum prohibitorum et expurgatorum index del 1707, preparado en tiempos del Inquisidor general Diego Sarmiento de Valladares, y por el que pasaron personalidades de ámbito jurídico como Andreas Alciatus, Antonius Faber, Dionysio Gothofredus, Franciscus Duarenus, Franciscus Hottomanus, Franciscus Vitoria, Hugo Donellus, Hugo Grotius, Iacobus Menochius entre otros ${ }^{55}$.

En tal contexto hay que destacar también la labor cultural que realizó la Compañía de Jesús, tanto en Europa como en Indias, en donde fundaron colegios y universidades ya desde mediados del siglo XVI, centros que pronto necesitaron de enormes cantidades de libros ${ }^{56}$. A tal propósito la Compañía de Jesús estableció un Procurador General de Indias en la ciudad de Sevilla para que se encargue de hacer llegar las peticiones desde las Indias a la Corte, y facilitar también los trámites de embarque ante la Casa de Contratación en Sevilla ${ }^{57}$, pero sobre todo, recibía de los colegios y universidades en Indias el dinero necesario para la compra de libros, que una vez adquiridos los enviaba. A tal respecto el Procurador negociaba con antelación la compra de grandes cantidades de libros especialmente en España, Italia, Flandes y Francia para conseguirlos a buen precio, por lo que en sus registros aparece el iter a través del cual estos llegaban a los destinatarios de las obras enviadas ${ }^{58}$.

Y resulta abundante la cantidad de literatura jurídica que venía embarcada en las naves destinadas a las Indias para uso universitario, de abogados y de los funcionarios de los organismos de la Corona española en tales territorios ${ }^{59}$.

\section{Algunas ediciones impresas del Digesto en los fondos antiguos de Santa Fe de Bogotá y de San Francisco de Quito}

Por lo que se refiere a las ediciones del Digesto y a la correspondiente bibliografía de los siglos XVI-XVIII que se encuentran en los Fondos antiguos de los archivos y

\footnotetext{
${ }^{54}$ Cfr. F. Betancourt, La recepción del derecho romano en Colombia (Saec. XVIII) cit., pp. 523.

${ }^{55} \mathrm{Y}$ donde la expurgación de las obras de derecho patrimonial de los grandes juristas europeos protestantes quedaban cobijadas bajo la tercera regla (del Quiroga de 1583/4) del Índice expurgatorio, y afectaba casi exclusivamente a la materia matrimonial, cfr. F. Betancourt, La recepción del derecho romano en Colombia (Saec. XVIII) cit., pp. 532.

${ }^{56}$ Vd. F. Betancourt, La recepción del derecho romano en Colombia (Saec. XVIII) cit., pp. 540.

${ }^{57} \mathrm{Vd}$. Recopilación de leyes de los Reinos de las Indias cit., libro IX, título I (De la Real Audiencia y Casa de Contratación que reside en Sevilla); J. Cervera Pery, La casa de contratación y el consejo de Indias (Las razones de un superministerio), Madrid, 1997.

${ }^{58}$ Cfr. F. Betancourt, La recepción del derecho romano en Colombia (Saec. XVIII) cit., pp. 541.

${ }^{59}$ Cfr. F. Betancourt, La recepción del derecho romano en Colombia (Saec. XVIII) cit., pp. 543.
} 
bibliotecas de las ciudades de Santa Fe de Bogotá y San Francisco de Quito, podemos exponer un elenco de las mismas empezando en primer lugar por aquellas que se encuentran en la Universidad -Colegio Mayor- de Nuestra Señora del Rosario, y en la Universidad Javeriana de Bogotá, según las referencias de Betancourt ${ }^{60}$, quien para la primera institución académica sigue el catálogo $B C M R$ (s.f. [ca.1924]), y para la segunda (Ed.) J. Del Rey Fajardo, S.J., La biblioteca colonial (2003) ${ }^{61}$ :

1. Justinianus. Digestum vetus. Pandectarum iuris civilis. Tomus I continens primam, tertiam partes ac quartae libros quatour (Lugduni [Imp. Ioanis Ausulti] 1566) (p. 121);

2. Justinianus. Infortiatum seu pandectarum iuris civilis. Tomus II, quartae partis reliquum itemque quintam partem ac sextae libros duos continens. Commentariis Accursii (Augustae Taurinorum [Imp. Haered. Nicolai Bevilaquae] 1576) (p. 122);

3. Justinianus. Corpus Iuris Civilis prudentum responsa Caesarumque rescripta complectens (Lugduni 1591) (p. 122);

4. Gothofredus I. C., Dionysius, Corpus Iuris Civilis. Vol. I-II (¿ ? [Imp. Iacobi Stoer] 1594 (p. 117);

5. Justinianus. Corporis Iuris Civilis pars illa quae Parvum volumen vocant (Lugduni [Imp. Gabrielis Carterii] 1600) (p. 121);

6. Gothofredus, Dionysius, Corpus Iuris Civilis in IV partes distinctum (Lugduni [Imp. Petri et J. Chouet] 1626) (p. 117)

Por lo que se refiere a la bibliografía sobre el Digesto, tenemos:

1. Baldus, Ubaldus Perusinus:

a. Commentaria in Digestum novum. Accessit tractatus de Pactis et de Constituto (Venetiis [Imp. Iac. Juntae] 1572) (p. 102);

b. In primam et secundam Infortiati partem acutissima commentaria adnotationibus doctossimorum iurisconsultorum praecipuae Francisci Curtii illustrata, atque ab infinitis mendis quibus uniquique scatebant...(Auguastae Taurinorum [Apud haeredes Nicolae Bevilaquae] 1580) [N. 1107b];

c. In primam et secundam Digesti novi partem acutissima commentaria... (Augustae Turinorum [Apud haeredes Nicolae Bevilaquae] 1580) [N. 1107c]

2. BARTOLUS DE SAXoferrato:

a. Secunda pars Commentariorum super Digesto Novo (Lugduni [Imp. Sebastiani Griphis] 1527) (p. 103);

\footnotetext{
${ }^{60} \mathrm{~F}$. Betancourt, La recepción del derecho romano en Colombia (Saec. XVIII) cit., pp. 544 ss.

${ }^{61}$ El primero se identificará por la página entre paréntesis redondo, y el segundo por la entrada entre paréntesis cuadrado, vd. F. Betancourt, La recepción del derecho romano en Colombia (Saec. XVIII) cit., pp. 544 ss.
} 
b. Prima et secunda pars Commentariorum super Infortiato (Lugduni [Imp. Sebastiani Griphis] 1527) (p. 103);

c. Secunda pars Commentariorum super Digesto Veteri (Lugduni [Imp. Sebastiani Griphis] 1527) (p. 103);

d. Commentaria in secundam Infortiati partem. Praelectiones (Lugduni [Imp. Iac. et Io. Senetoniorum] 1546) (p. 103);

e. Commentaria in primam Infortiati partem D. Petri Pauli Parisii Cardinalis additionibus illustrata (Lugduni [Imp. Thomae Bertelli] 1547) (p. 103);

f. Commentaria in primam Digesti Novi partem D. Petri Pauli Parisii Cardinalis additionibus illustrata (Lugduni [Imp. Thomae Bertelli] 1547) (p. 103);

g. Commentaria in primam et secundam Digesti Veteris partem. Adnotationibus Alex., Barb., Seissell, Pom., Nicelli et aliorum (Augustae Taurinorum [Imp. N. Bevilaquae] 1577) (p. 103);

h. Commentaria in primam et secundam Digesti Novi partem cum adnotationibus Alex., Barb., Seissell, Pom., Nicelli et aliorum (Augustae Taurinorum [Imp. N. Bevilaquae] 1577) (p. 103)

\section{Castro, Paulus de:}

a. In primam et secundam partem Digesti veteris. Francisci Curtii aliorumque adnotationibus (Lugduni [Imp. Fratr. Senetoniorum] 1544) (p. 108) [N. 0888: obra de nueve tomos];

b. In primam et secundam partem Digesti veteris praelectiones. Ad candentis Salamandrae insigne (Lugduni [Imp. Fratr. Senetioniorum] 1548) (p. 108);

c. Avenionicae in Digestum vetus et novum praelectiones. Ad candentis Salamandrae insigne (Lugduni [Imp. Fratr. Senetionorum] 1544) (p. 108);

d. Prima et secunda pars super Digesto novo, elegantissimis Francisci de Curte apostillis et additionibus ac Repertorium super commentario (Lugduni [Imp. Sebastiani Gryphis] 1527) (p. 108);

e. In primam et secundam partem Digesti novi Francisci Curtii alioqumque adnotationibus (Lugduni [Imp. Fratr. Senetoniorum] 1544 (p. 108);

f. In primam et secundam Digesti novi partem Praelectiones Francisci Curtii adnotationibus illustrata. Ad candentis Salamandra insigne (Lugduni [Impr. Fratr. Senetoniorum] 1548) (p. 109)

4. Decius Mediolanensis, Phillipus, Digestum vetus et Codicem commentaria (Augustae Taurinorum [Imp. Nicolai Bevilaquae] 1575) (p. 111)

5. Donellus, Hugo, Commentarii absolutissimi ad titulum Digestorum (Francofurti [Imp. Petri Fischeri] 1599 (p. 112) [N. 0913 a) ed. de Francofurti 1599]

6. JASOn de Mayno Mediolanensis:

a. In primam et secundam Digesti veteris commentaria. Vols. I-II (Augustae Taurinorum [Imp. Nicolai Bevilaquae] 1573) (p. 119);

b. Prima et secunda super Digesto veteri cum additionibus Francisci Ioannis Purpurati. Vols. I-II (Lugduni [Imp. Petri Fradin] 1553) (p. 119);

c. In primam Digesti veteris partem commentaria cum additionibus doctissimi Joannis Francisci Bonavoglia (Venetiis [Imp. Iac. Iuantae] 1612) (p. 119); 
d. In secundam Digesti veteris partem commentaria (Venetiis [Imp. Iac. Juantae] 1622) (p. 119);

e. In primam et secundam partem Digesti novi commentaria (Augustae Taurinorum [Imp. Nicolai Bevilaquae] 1573) (p. 119);

f. In primam Infortiati partem commentaria (Augustae Taurinorum) [Imp. Nicolai Bevilaquae] 1573) (p. 119);

g. Prime et secunda pars super Infortiato cum additionibus Joannis Francisci Purpurati. Vols. I-II (Lugduni [Imp. Blasii Guido] 1553) (p. 123)

7. Rebuffo de Montepessulano, Petrus, In titulum Digesti de verborum et rerum significatione commentaria amplissima (Lugduni [Apud Haeredes Gulielmi Rovillii] 1614) [N. $1048 \mathrm{a}]$

8. RiPA, JoANNES FRANCISCUS, In primam et secundam Infortiati partem commentaria (Venetiis 1602) (p. 130)

9. Socinus Senensis, Bartholomeus:

a. In Digestis Veteris ac Infortiati rubricas, leges atque omnes Gymnasii usitatiores. Ed. Postrema (Venetiis [Imp. Juntae] 1605) (p. 132);

b. In Digesti novi ac Codicis rubricas, leges atque omnes in Gymnasiis uisitatores. Ed. postrema (Venetiis [Imp. Juntae] 1605) (p. 132);

c. Ad Digestum novum et aliquot Codicis titulos. Editi per Vincentium Godemianum Pistorien. J. D. (Lugduni [Imp. Claudii Servanii] 1564) (p. 132)

Por lo que se refiere a las ediciones impresas del Digesto, y su correspondiente bibliografía, que se encuentran en la ciudad de San Francisco de Quito, podemos indicar aquellas del 'Fondo antiguo de los Jesuitas' situado en la Casa de la Cultura ecuatoriana:

1. Justinianus I, imp. Digestorum seu Pandectarum libri quinquaginta ex Florentinus Pandectis Representatis (Florentiae, in oficina Laurentii Torrentini ducalis typographi) 1553. [ML. ${ }^{62} 1138$ ius];

2. Justinianus I, imp. Digestum vetus, seu Pandectarum iuris civilis tomus primus [secundus], ex Pandectis Florentinis Representatus: commentariis Accursij, \& multorum insuper aliorum ...illustratum (Antverpiae) 1575, 2 vols. [ML. 2010-2011];

3. Justinianus I, imp. Digestorum novum, seu Pandectarum iuris civilis tomi...commentariis Accursij (Antverpiae) 1575 [ML. 1508];

4. Justinianus I, imp. Digestum vetus, seu Pandectarum iuris civilis (Antverpiae [Apud Christophorum Plantium] 1575) [ML. 1073 ius];

5. Justinianus I, imp. Pandectarum seu Digestum vetus iuris civilis tomi cum Pandectis

${ }^{62}$ Iniciales que indicaban 'Museo del Libro', así en origen catalogado. 
Florentinis, quae olmi pisanae dicebantur, diligentissime collatus...commentariis Accursii, \& multorum insuper aliorum ...praecipue (Venetiis 1591) [ML. 1114 ius];

6. Justinianus I, imp. Pandectarum seu Digestorum iuris civilis domini Iustiniani...tomus tertius. Quod Digestum novum vulgo appelant. Cum Accursij commentarijs..., editio postrema (Venetiis 1591) [ML. 1044 ius];

7. Justinianus I, imp. Corpus iuris civilis, quo in universum iustinianeum comprehenditur... Codice cum optimis quibusque editionibus collato cum notis repetitae quantum praelactionis Dionysii Gothofredi I.C. Additae et institutionum Novellarum Iustiniani, Leonis \& feudorum epitomae edictum perpetum. Graecae leges \& constitutions in Pandectis \& Codice leges XII tabul... (Lutetiae Parisiorum 1628), 2 vols. [ML. 4421-4422];

8. Justinianus I, imp. Corpus iuris civilis in IV partes distinetum. Eruditissimis Dionysii Gothofredi I.C. calrissimi notis illustratum (Lugdugni 1662) [ML. 1313];

9. Justinianus I, imp. Digestorum seu Pandectarum pars sexta liber XXXVII-XL (s.n.t. 1666) [ML. 1528]

En lo relativo a la bibliografía sobre el Digesto, tenemos:

1. Bartoli a Saxoferrato, Secunda super Digesto novo. Insunt huic vol...Alexandri Losaei Aveliani iurisconsulti opera (Lugduni 1541) [ML. 1712]

2. Mayner, Guillaume, Commentaria in titulum Pandectarum, de Regulis iuris (Lugduni 1545) [ML. 116 May]

3. CuJAs, JACQues, Paratitula in libros quinquaginta Digestorum seu Pandectarum Imperatoris Iustiniani/opus Iacobi Cujacij (Venetiis 1572) [ML. 4650]

4. Rebuffi, Pierre, Explicatio ad quatuor primos Pandectarum libros. Auctore d. Pietro Rebuffo de Montepessulam (Lugduni 1589) [ML. 1674]

\section{Observaciones conclusivas}

Se ha intentado mostrar algunos de los aspectos concernientes a la circulación de las primeras ediciones impresas del Digesto que se encuentran en las ciudades de Santa Fe de Bogotá y de San Francisco de Quito, y así conocer algunas de las pautas más relevantes que marcaron el iter por el cual llegaron hasta su destino, y poder además comprender cómo el derecho romano sirvió de instrumento para el aprendizaje y para la práctica jurídica en tal contexto territorial.

Por lo que concierne las ediciones del Digesto que se encuentran en la ciudad de Santa Fe de Bogotá, me he servido de las referencias expuestas en la monografía del Profesor Fernando Betancourt ${ }^{63}$, mientras que para las ediciones que se encuentran

${ }^{63}$ F. Betancourt, La recepción del derecho romano en Colombia (Saec. XVIII) cit., pp. 544 ss. 
en la ciudad de San Francisco de Quito, he podido constatar directamente la presencia de las mismas en la Casa de la Cultura ecuatoriana. Sin embargo, el elenco de las ediciones que se encuentran en esta última ciudad no es más que un ejemplo mínimo de lo que realmente poseen los varios Fondos desplegados en Quito ${ }^{64}$, sin olvidar la existencia de Fondos y archivos situados en los conventos quiteños, como el de San Francisco, Santo Domingo y San Agustín, en donde con seguridad existen ediciones impresas de la obra de Justiniano del período aquí tomado en consideración.

Hay que tener en cuenta también que lo conservado hasta la actualidad en dichos Fondos no es sinónimo de lo que efectivamente llegó desde Europa hasta estos territorios, ya que muchas de las ediciones del Digesto que se transportaron pudieron haberse extraviado o destruido durante el transcurso de los siglos, siendo a tal respecto más exhaustivo proceder a una consultación en el Archivo de Indias de Sevilla, en particular en los registros sobre las cargas de libros que las naves españolas transportaron hasta dichos territorios durante el período de la colonia en Ultramar.

${ }^{64}$ Actualmente algunos de estos Fondos se encuentran en fase de restauración y de catalogación. 